\title{
Piezoelectric,0ptical and Electrical Characterization of Vertical ZnO Nanowires
}

\author{
Marwa Bakour ${ }^{1 *}$,Batal M A ${ }^{1}$ and Amir AlhajSakur ${ }^{2}$ \\ ${ }^{1}$ Department of Physics, Syria \\ ${ }^{2}$ Analytical and Food Chemistry Department, Syria \\ *Corresponding author: MarwaBakour, Department of Physics, Aleppo, Syria \\ Submission: 制 April 01, 2018; Published: 眥 July 02, 2018
}

\begin{abstract}
Oxide nanowire arrays were studied for piezoelectric applications.Such as $\mathrm{ZnO}$ nanowire arrays growth on silicon substrate. The effects of thermal annealing on the optical properties of $\mathrm{ZnO}$ nanowires were prepared on sol-gel $\mathrm{ZnO}$-seed-coated substrates. AFM images were found at $130^{\circ} \mathrm{C}$ well aligned vertically, and the well defined crystallographic planes, providing strong evidence that the nanowire arrays orientate along the c-axis. The annealing temperature of the $\mathrm{ZnO}$ thin film plays an important role on the microstructure of the $\mathrm{ZnO}$ grains and then the growth of the $\mathrm{ZnO}$ nanowire arrays. From PL spectra, an evident ultraviolet near-band edge emission peak at $382 \mathrm{~nm}$ is observed.From (I-V) characteristic that the material behaves p-n junction diode, ideality factors $>>2.0$, that was attributed to tunnelling via deep levels in the forbidden gap. Impedance spectra shows the spectrum of the Impedance resistance that the curve does not represent a regular semicircle andthis indicates that the structure of the material is not regulated granules but rather is in a different form which is the nanowires. From Piezoelectric characterization, voltage increase with increase the force applied on Nanowires.
\end{abstract}

Keywords:C-axis ZnO nanowires; ZnO seed layer; Sol-Gel;AFM images; PL spectra; (I-V) characteristics; Ideal factor;Impedance spectra;Piezoelectric characterization

\section{Introduction}

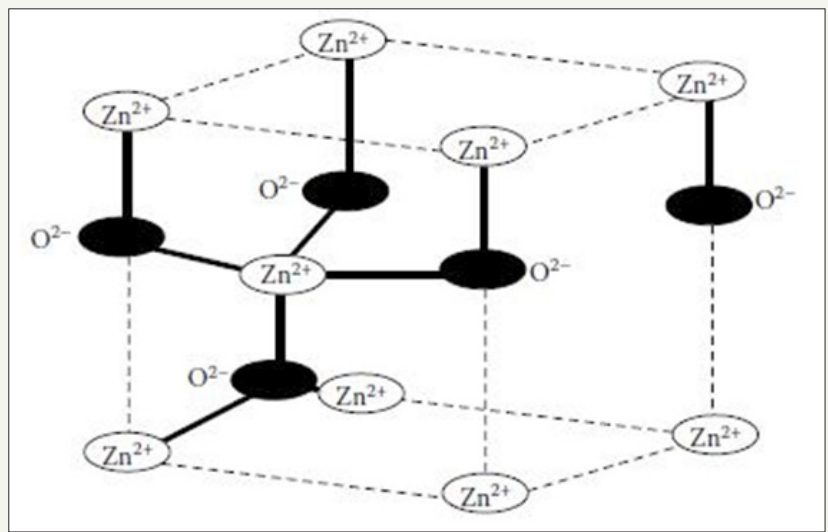

Figure 1: Hexagonal wurtzite structure of $\mathrm{ZnO}$.

In recent years, zinc oxide $(\mathrm{ZnO})$ has attracted a lot of attention because of its interesting physical properties such as its wide and direct band gap $(3.37 \mathrm{eV})$, large exciton binding energy $(60 \mathrm{meV})$, high electron mobility, and high thermal conductivity [1], exhibiting near UV light emission, transparent conductivity, hexagonal crystal structure (Figure 1). These features render ZnO suitable for several applications ranging from optoelectronics [2], piezoelectric and photovoltaic systems [3]. In this research we try to find a way to convert mechanical energy into electric power with the use of aligned zinc oxide $(\mathrm{ZnO})$ nano wires. The mechanism of the power generator relies on the coupling of piezoelectric and semiconducting properties of $\mathrm{ZnO}$ as well as the formation of a Schottky barrier between the metal and ZnO contacts. One-dimensional $\mathrm{ZnO}$ nanostructures such as nano wires have been extensively studied for other applications including solar cells [4], ultraviolet (UV) light-emitting diodes [5], photonic crystals and transparent electrodes [6]. Several methods have been demonstrated to fabricate one-dimensional $\mathrm{ZnO}$ nanostructures, 
such as vapour liquid solid epitaxial (VLSE), chemical vapour deposition (CVD) [7]. However, the high temperatures required for these gas deposition techniques (above $500^{\circ} \mathrm{C}$ for $\mathrm{CVD}$ and $900^{\circ} \mathrm{Cfor}$ VLSE) and pulse laser deposition (PLD) [8], but these techniques still have some limitations for substrate size and the need for high temperature operation.

Recently, the growth of $\mathrm{ZnO}$ nano wires in phase solutions at low temperature (below $100{ }^{\circ} \mathrm{C}$ ) was reported by using the hydrothermal process, the growth had been on glass, silicon wafer and plastic substrates [9]. This method shows that the shape of the $\mathrm{ZnO}$ nano wires was sensitive to the orientation of Si substrate via the use of $\mathrm{ZnO}$ nano particles as a seed layer. However, systematic research on the influence of quality characteristics of $\mathrm{ZnO}$ sol-gel thin films on the growth of $\mathrm{ZnO}$ nano wire arrays via hydrothermal method has rarely been reported. In this work, now catalytic method and $\mathrm{ZnO}$, cost effective, non-catalytic method and $\mathrm{ZnO}$ sol-gel thin films were used as the seed layers with different temperatures annealing.

\section{Experimental details}

\section{Upturned crystalline growth method is two phases:}

A. Preparation seed layer thin films: The $\mathrm{ZnO}$ thin films served as the seed layers were deposited on silicon substrates by a sol-gel method [10]. A coating solution contained zinc acetate dehydrate $\left(\mathrm{Zn}\left(\mathrm{CH}_{3} \mathrm{COO}\right) 22 \mathrm{H}_{2} \mathrm{O}\right.$, Merck, $99.5 \%$ purity) and equivalent molar mono ethanolamine (MEA) $\left(\mathrm{NH}_{2} \mathrm{CH}_{2} \mathrm{CH}_{2} \mathrm{OH}\right.$, Merck, 99.5\% purity) dissolved in 2-methoxyethanol (2MOE) $\left(\mathrm{CH}_{3} \mathrm{OCH}_{2} \mathrm{CH}_{2} \mathrm{OH}\right.$, Merck, $99.5 \%$ purity). The concentration of zinc acetate was chosen to be $0.5 \mathrm{~mol} / \mathrm{L}$. The resulting solution was then stirred at $60^{\circ} \mathrm{C}$ for $2 \mathrm{~h}$ to yield a homogeneous solution, which served as the coating solution after being cooled to room temperature. Then the solution was coated onto p-type silicon (111) substrates by a spin coater at the rate of $1000 \mathrm{rpm}$ for $30 \mathrm{~s}$ at room temperature. Subsequently, the films were preheated for $10 \mathrm{~min}$ to remove the residual solvent. Then the layer film was annealed in a furnace at different temperatures ranging from 130 to $900{ }^{\circ} \mathrm{C}$ for $2 \mathrm{~h}$.

B. Growth Vertical ZnO Nano wires arrays: After uniformly coating the silicon substrates with $\mathrm{ZnO}$ thin films, growth of $\mathrm{ZnO}$ nano wire arrays was achieved by suspending these $\mathrm{ZnO}$ seed-coated substrates upside down in a glass beaker filled with solution of $50 \mathrm{mM}$ zinc nitrate hexa hydrate $\left(\mathrm{Zn}\left(\mathrm{NO}_{3}\right)_{2} 6 \mathrm{H}_{2} \mathrm{O}\right.$, $98 \%$ purity) and $50 \mathrm{mM}$ hexamethylenetetramine (HMT) $\left(\mathrm{C}_{6} \mathrm{H}_{12} \mathrm{~N}_{4}, 99.5 \%\right.$ purity $)$. During the growth, the glass beaker was heated with a laboratory oven maintained at $60^{\circ} \mathrm{C}$ for $12 \mathrm{~h}$. At the end of the growth period, the substrates were removed from the solution, then immediately rinsed with de-ionized water to remove any residual salt from the surface, and dried in air at room temperature.

\section{Results and Discussion}

\section{Surface morphologies (AFM Images)}

Figure 2 shows the AFM images for the surface morphologies of $\mathrm{ZnO}$ nano wire arrays at different annealing temperatures of the thin films. It is notable that the $\mathrm{ZnO}$ nano wire arrays on the $\mathrm{ZnO}$ thin films annealed at $130{ }^{\circ} \mathrm{C}$ are well aligned vertically (Figure $2 \mathrm{a}$ ), and the well defined crystallographic planes, providing a strong evidence that the nano wire arrays orientate along the c-axis. This implies its perfect c-axis orientation. As the annealing temperatures of the $\mathrm{ZnO}$ thin films increase from 130 to $900{ }^{\circ} \mathrm{C}$, the diameters of the $\mathrm{ZnO}$ nano wire arrays increase from 10 to $80 \mathrm{~nm}$ in average and its high ranging from 300 to $400 \mathrm{~nm}$. The reason may be that the high annealing temperature evidently increase the interaction among the grains and leads the grains to merge together to form bigger $\mathrm{ZnO}$ seeds, and thus increases the diameter of the $\mathrm{ZnO}$ nano wires Figure 2b-2d.

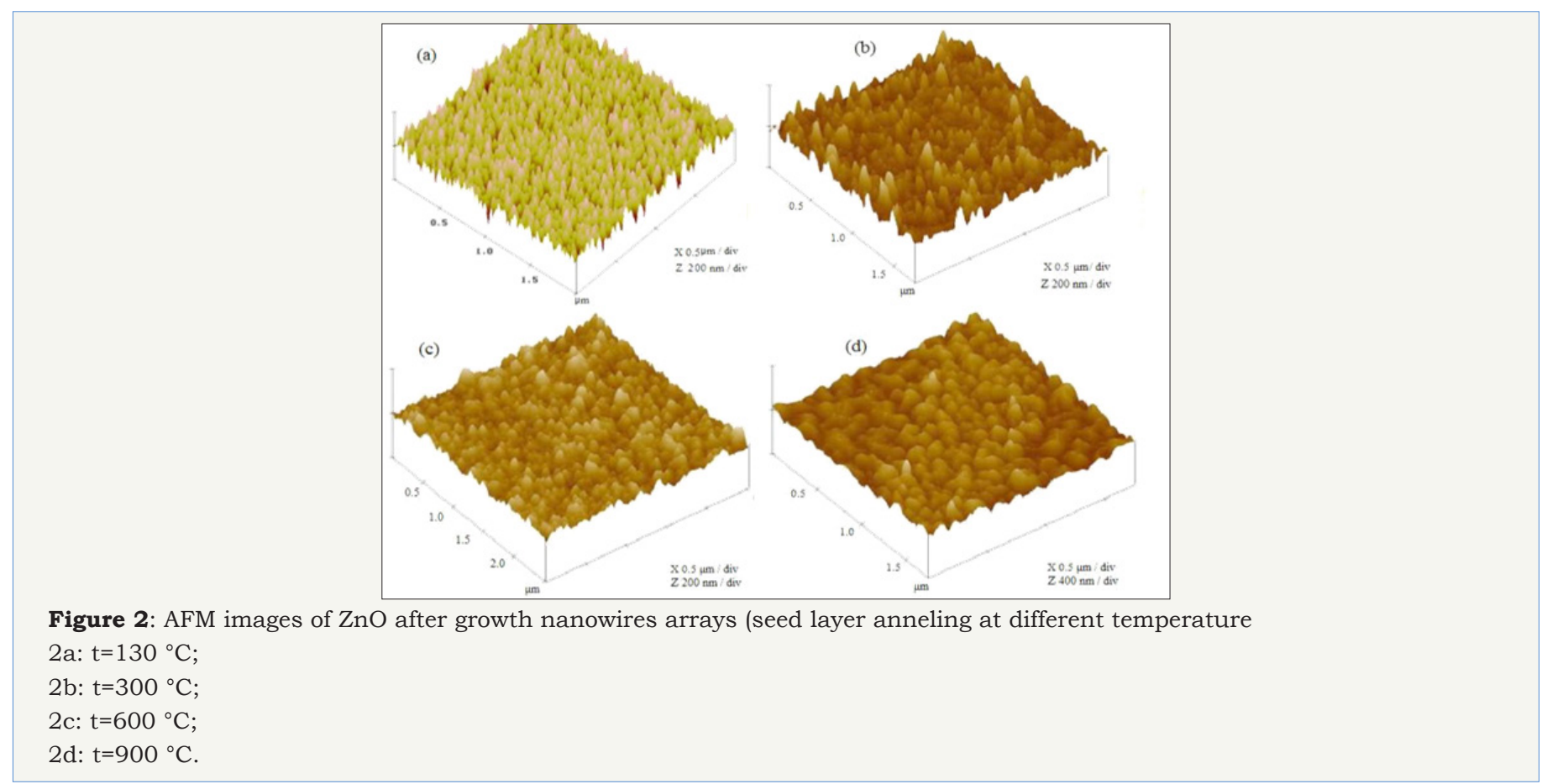




\section{Electrical properties}

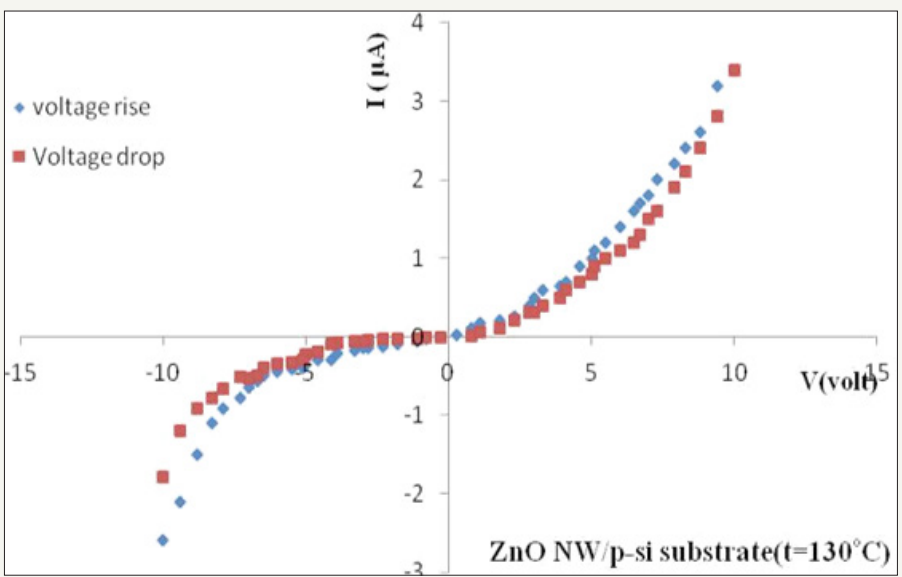

Figure 3: I-V characteristics of Nanowires $\mathrm{ZnO}$ that seed layer annealing at $130{ }^{\circ} \mathrm{C}$.

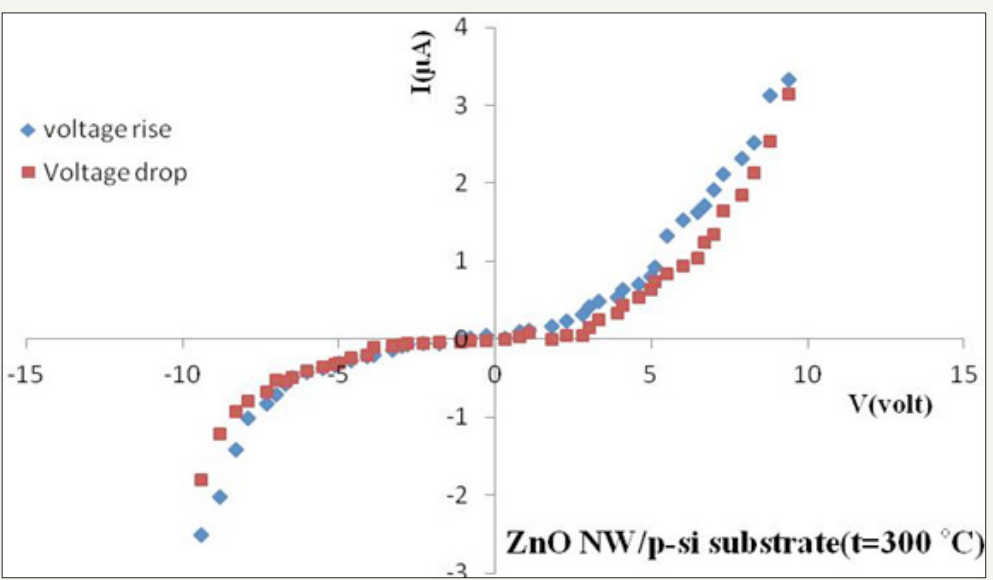

Figure 4: I-V characteristics of Nanowires $\mathrm{ZnO}$ that seed layer annealing at $300{ }^{\circ} \mathrm{C}$.

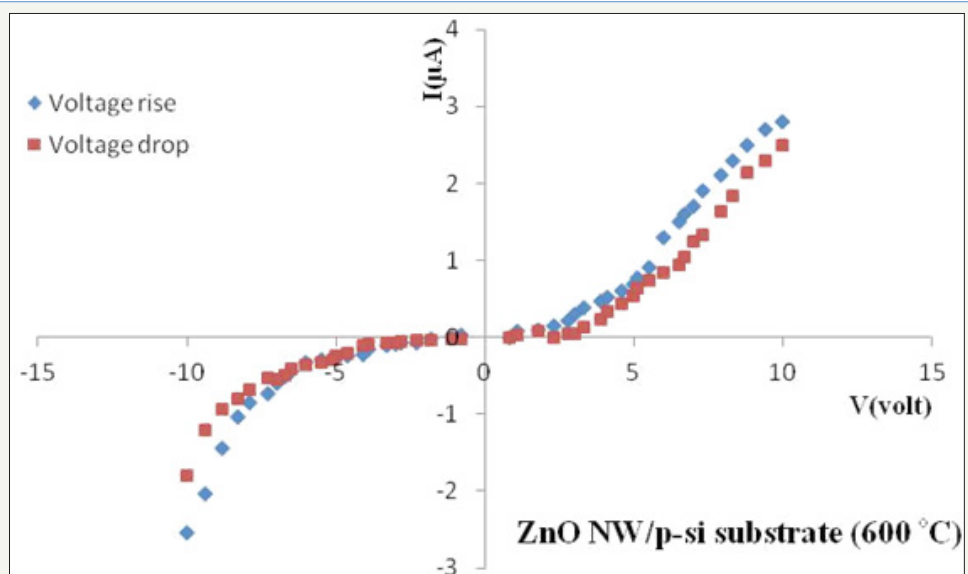

Figure 5: I-V characteristics of Nanowires $\mathrm{ZnO}$ that seed layer annealing at $600{ }^{\circ} \mathrm{C}$.

(I-V) Curves for ZnO Nano wire arrays: I-V characteristics of Nano wires $\mathrm{ZnO}$ arrays measured at room temperature are shown in Figure 3-7. Figure 3-7 shows that at constant voltage, the current value of the voltage is increase than its value in case of voltage decrease there is a slow loop. This is due to the fact that while lifting the applied voltage, the ions on the trap level have moved to another more closely related crystalline structure leading to decreasing charge carriers during the decrease in applied voltage and thus the current decline. Note from the (I-V) characteristic that the material behaves p-n junction diode. As per the Sah-NoyceShockley theory [11], the forward current in a p-n junction is dominated by recombination of minority carriers injected into the neutral regions of the junction. This type of current gives an ideality factor of 1.0. Recombination of carriers in the space charge region, mediated by recombination centers located near the intrinsic Fermi level, results in an ideality factor of 2.0 [12]. The high ideality factors $(n>>2.0)$ in LEDs or $p-n$ junction diode were attributed to deeplevel-assisted tunneling, due to temperature-independent slopes of 
( $\log$ I)-versus-V plots. Ideality factors close to 2.0 were attributed to space charge region recombination, consistent with the Sah-NoyceShockley theory, due to temperature-dependent slopes of (log I)-versus-V plots. However, a comprehensive theory for the high ideality factors found experimentally in p-n junctions has not been presented. The ideal factor can be calculated by drawing the graph of $\operatorname{Ln}(\mathrm{I})$ with $\mathrm{V}$ as in Figure 8.

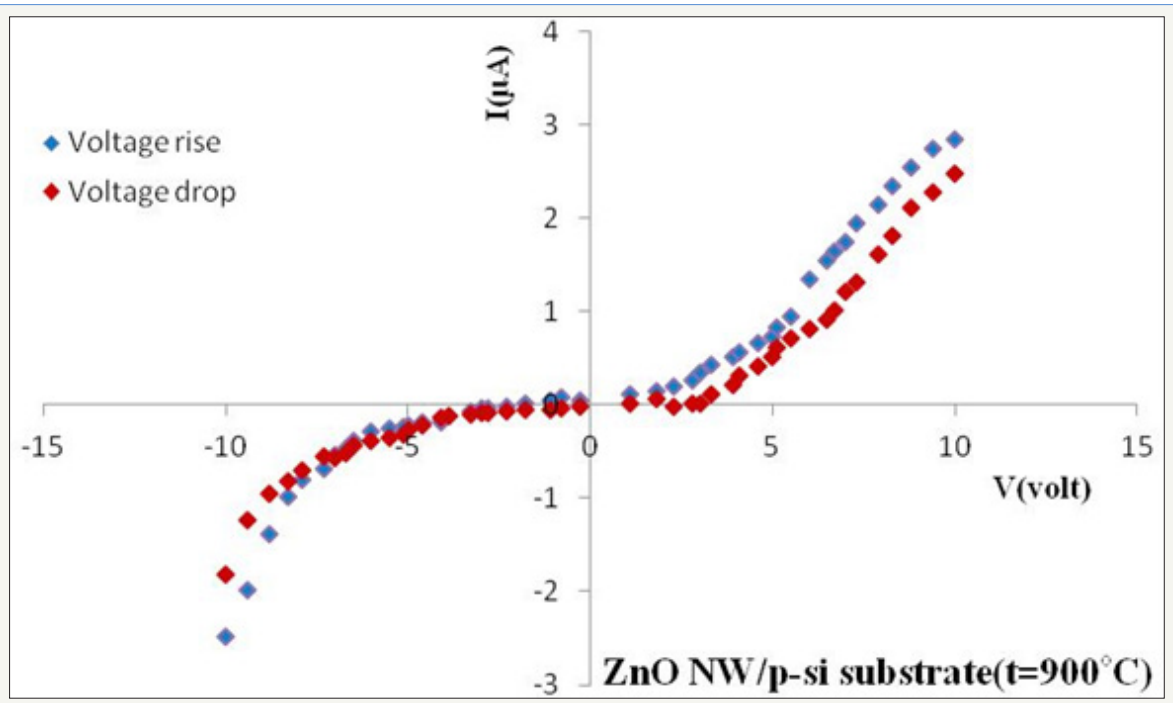

Figure 6: $\mathrm{I}-\mathrm{V}$ characteristics of nanowires $\mathrm{ZnO}$ that seed layer annealing at $900{ }^{\circ} \mathrm{C}$.

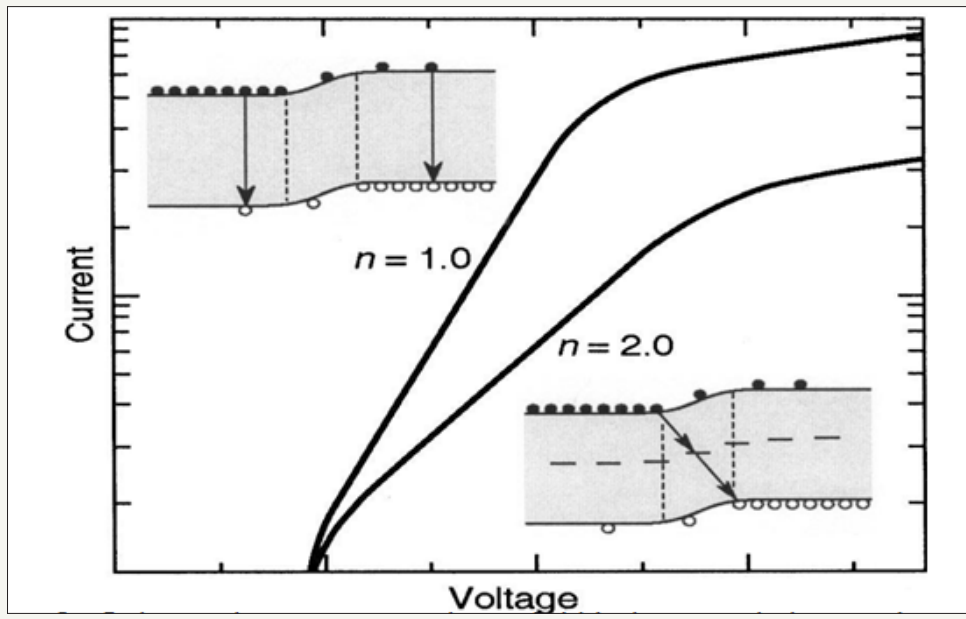

Figure 7: Schematic representation of $\mathrm{I}-\mathrm{V}$ characteristics and carrier transport mechanism for diode ideality factors of $\mathrm{n}=1.0$ and $n=2.0$.

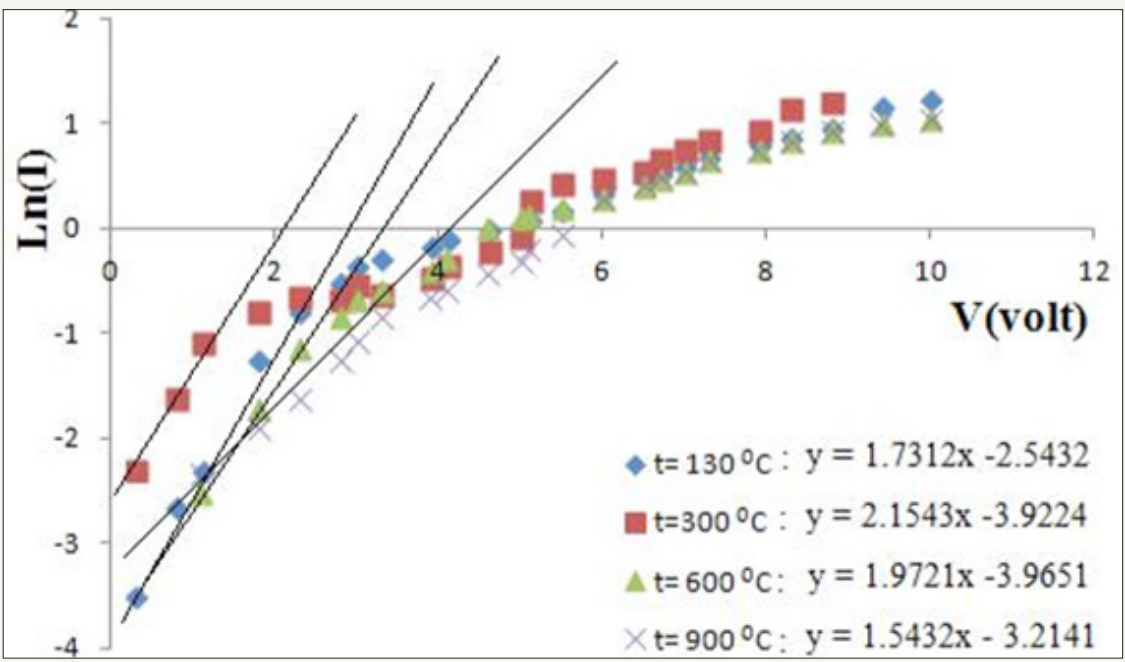

Figure 8: (Ln (I)-V) in the forward bias voltage range at voltage rise. 
The ideal factor of the equation (1) can be calculated:

$$
\ln (I)=\frac{q}{k T} V n(1)
$$

Where $\mathrm{q}$ is the elementary charge, $\mathrm{k}$ is the Boltzmann constant, $\mathrm{T}$ is the absolute temperature, and $\mathrm{n}$ is the ideality factor. Where attention is given to the linear area of the curve [13]. The ideal factor values were arranged in Table 1 it is apparent that ideality factors $>>2.0$ can be measured, that was attributed to tunneling via deep levels in the forbidden gap.

Table 1: Ideal factor values.

\begin{tabular}{|c|c|c|c|c|}
\hline $900^{\circ} \mathrm{C}$ & $600{ }^{\circ} \mathrm{C}$ & $300^{\circ} \mathrm{C}$ & $130^{\circ} \mathrm{C}$ & Temperature \\
\hline 25.58 & 20.02 & 18.33 & 22.81 & Ideal factor \\
\hline
\end{tabular}

Impedance spectra measurements: Using a gain phase analyzer devise type (Schlumberger-SI1253) with detection resistance $\mathrm{Rd}$. A variable frequency signal $[0.1 \mathrm{~Hz}-20 \mathrm{KHz}]$ was applied to the material and a fixed input voltage $(\mathrm{V} 1=5 \mathrm{v})$ was applied. To determine the spectrum of impedance spectra, the equation (2) can be used:

$$
Z(\omega)=R(\omega)+j X(\omega)(2)
$$

Table 2: Deceleration time values at different annealing temperature.

\begin{tabular}{|c|c|c|c|c|}
\hline $\mathbf{t}\left(\mathbf{~}^{\mathbf{0}} \mathbf{C}\right)$ & 130 & 300 & 600 & 900 \\
\hline $\mathbf{R}(\omega)$ & 2509.161 & 2589.2 & 2690.87 & 2755.87 \\
\hline $\mathbf{f}(\mathbf{H z})$ & 183.5 & 198.5 & 250.1 & 309.1 \\
\hline $\mathbf{T}(\mathbf{s e c})$ & 0.000867 & 0.000802 & 0.000636 & 0.000515 \\
\hline
\end{tabular}

Figure 9 shows the curves are regular semicircles. So the structure of the granular material in the seed layer represents the equivalent circuit between the granules is intense and connected in parallel with the resistance. Figure 10 shows the spectrum of the Impedance resistance that the curve does not represent a regular semicircle and this indicates that the structure of the material is not regulated granules but rather is in a different form which is the nano wires [14]. The time of deceleration $(\tau)$ of the electron can be determined by drawing the real section of the impedance with frequency as shown in Figure 11. Since the deceleration time is equal to the inverted frequency at the top of the curve (Table 2).

$$
\tau=\omega 1=21 \pi f
$$

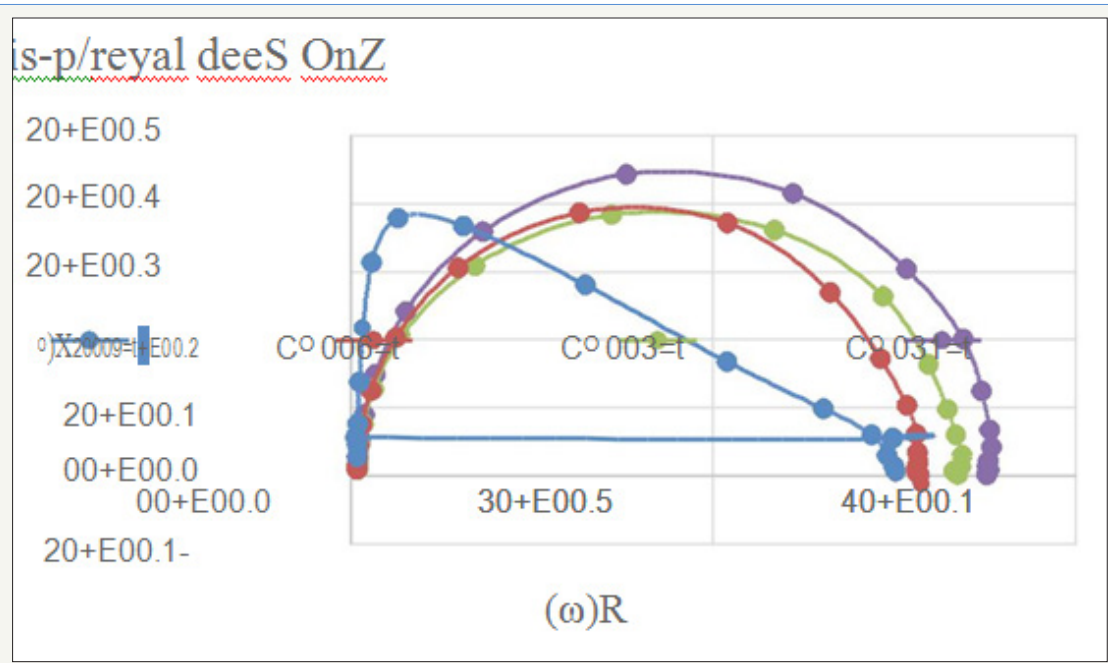

Figure 9: Impedance spectra scope of $\mathrm{ZnO}$ Seed layer deposits on $\mathrm{p}$-Si.

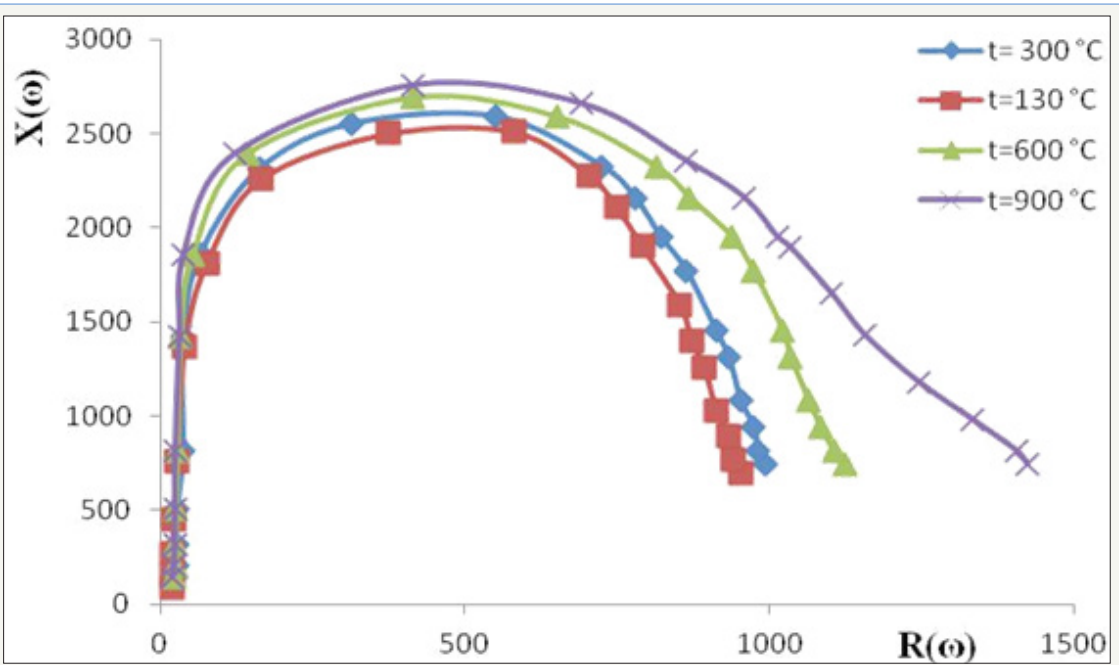

Figure 10: Impedance spectra scope of $\mathrm{ZnO}$ nanowires arrays growth on $\mathrm{p}$-Si. 


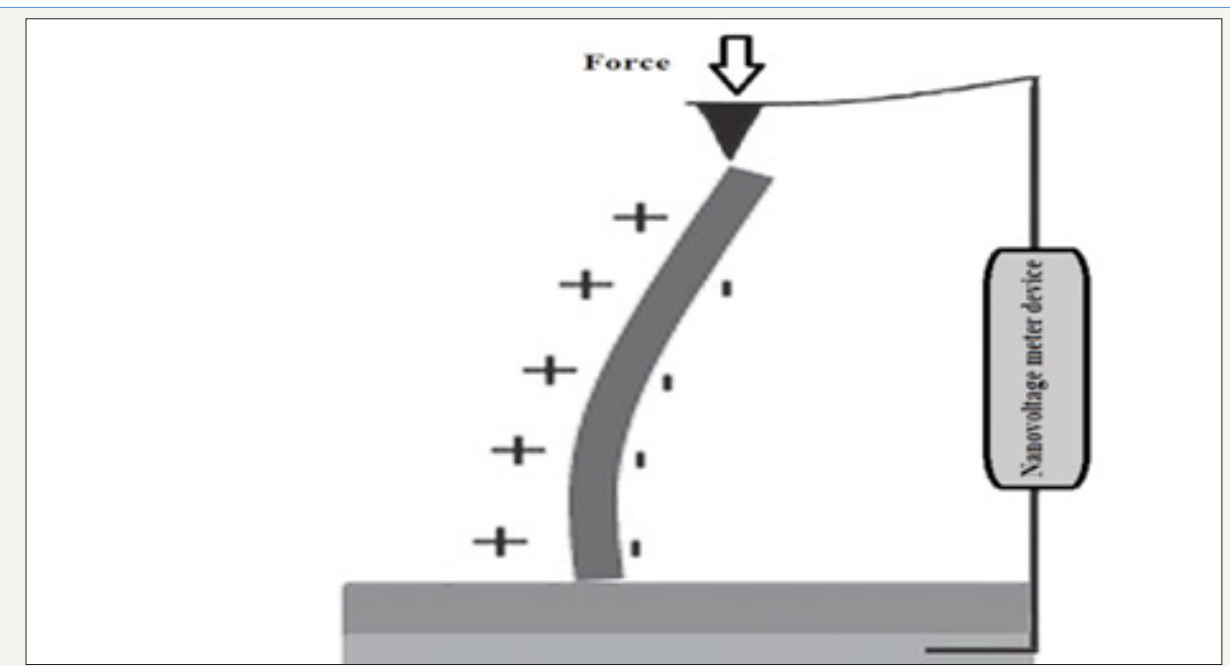

Figure 12: The force applied on $\mathrm{ZnO}$ nanowires and voltage measurement.

\section{References}

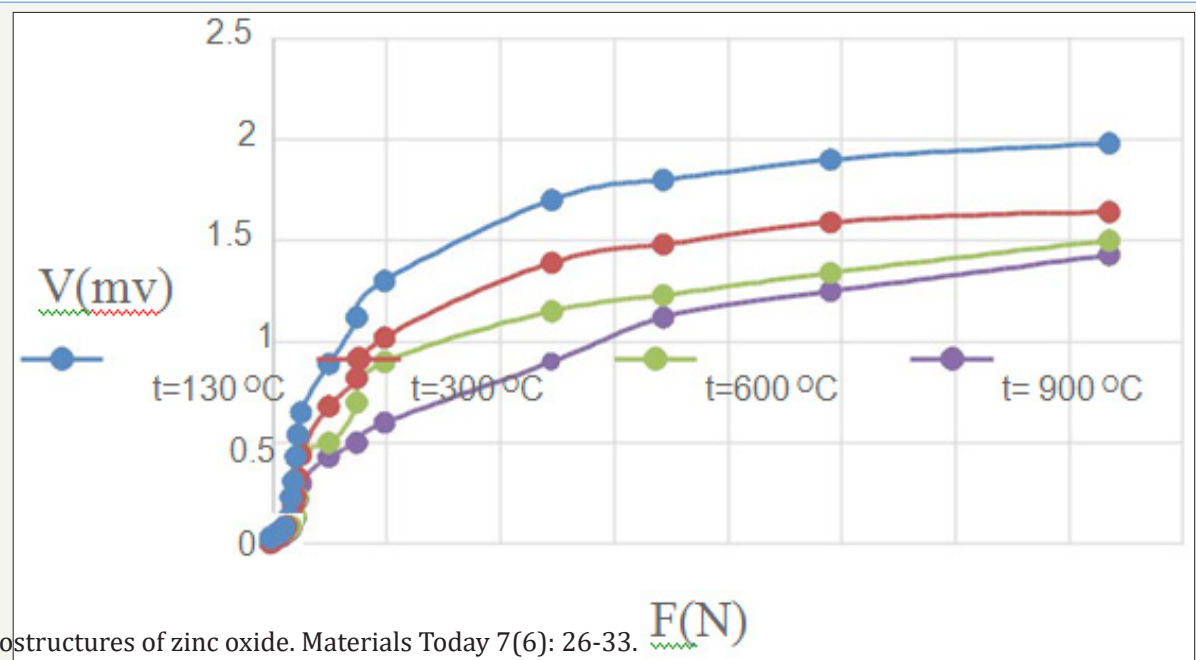

1. Zhong LW (2004) Nanostructures of zinc oxide. Materials Today 7(6): 26-33. F(N)

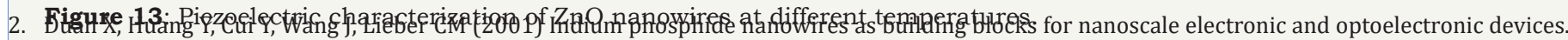
Nature 409(6816): 66-69.

3. Ozgur YI, Alivov C, Liu A, Teke MA, Reshchikov S, et al. (2005) Growth of ZnO nanolayers inside the capillaries of photonic crystal fibre. J Appl Phys 98: 041301.

4. Law M, Greene LE, Johnson JC, Saykally R, Yang PD (2005) Nanowire dye-sensitized solar cell. Nature Materials 4: 455-459.

5. Lim JH, Kang CK, Kim KK, Park IK, Hwang DK, et al. (2006) UV electroluminescence emission from ZnO eight-Emitting diodes grown by high temperature radiofrequency sputtering. Adv Mater 18(20): 2720-2724.

6. Znaidia L, Touamb T, Vrela D, Soudeda N, Yahiaa SB, et al. (2012) ZnO thin films synthesized by sol-gel process for photonic applications. Acta Physica Polonica A 121(1): 165-168.

7. Ikegami K, Yoshiyama T, Maejima K, Shibata H, Tampo H, et al. (2009) Optical dielectric constant inhomogeneity along the growth axis in ZnO-based transparent electrodes deposited on glass substrates. J Appl Phys 105: 093713-093719.

8. Wu JJ, Liu SC (2002) Low-temperature growth of well-aligned ZnO nanorods by chemical vapor deposition. Adv Mater 14(3): 215-218.

9. Varanasi CV, Leedy KD, Tomich DH, Subramanyam G, Look DC (2009) Improved photoluminescence of vertically aligned ZnO nanorods grown on $\mathrm{BaSrTiO}_{3}$ by pulsed laser deposition. Nanotechnology 20: 38 .

10. Yong Q Rusen Y, Zhong LW (2008) Growth of horizonatal zno nanowire arrays on any substrate. J Phys Chem C 112 (48): 18734-18736.

11. Shuxi D, Yang W, Dianbo Z, Xiao H, Qing S, et al. (2011) Fabrication of surface-patterned ZnO thin films using sol-gel methods and nanoimprint lithography. Journal of Sol-Gel Science and Technology 60: 17.

12. Tanvir A, Sharmin S, Faysal NM (2016) Comparative analysis between single diode and double diode model of PV cell: concentrate different parameters effect on its efficiency. Journal of Power and Energy Engineering 4(3): 31-46.

13. Jay MS, Li YL, Gessmann T, Schubert EF (2003) Experimental analysis and theoretical model for anomalously high ideality factors $(n>>2.0)$ in AlGaN/GaN p-n junction diodes. Journal of Applied Physics 94(4): 2627 2630.
14. Abdullah K, Bui A, Loubierre A (1991) Low frequency and low temperature behavior of $\mathrm{ZnO}$-based varistor by ac impedance measurements. Journal of applied phys 69(7): 4046-4052. 
Creative Commons Attribution 4.0 International License

For possible submissions Click Here

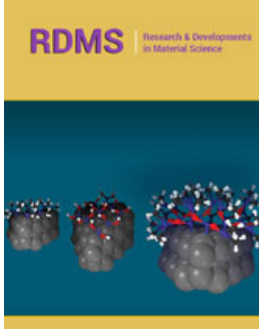

\section{Research \& Development in Material Science}

\section{Benefits of Publishing with us}

- High-level peer review and editorial services

- Freely accessible online immediately upon publication

- Authors retain the copyright to their work

- Licensing it under a Creative Commons license

- Visibility through different online platforms 